\title{
Development of microsatellite and mating type markers for the pine needle pathogen Lecanosticta acicola
}

\author{
J. Janoušek ${ }^{1 *}$, S. Krumböck ${ }^{2}$, T. Kirisits ${ }^{2}$, R. E. Bradshaw ${ }^{3}$, I. Barnes $^{4 \ddagger}$, L. Jankovský $y^{1 \ddagger}$, C. \\ Stauffer ${ }^{2+}$
}

${ }^{1)}$ Department of Forest Protection and Wildlife Management, Faculty of Forestry and Wood Technology, Mendel University in Brno, Brno 613 00, Czech Republic

${ }^{2)}$ Institute of Forest Entomology, Forest Pathology and Forest Protection, Department of Forest and Soil Sciences, University of Natural Resources and Life Sciences, Vienna (BOKU), Vienna, Austria

${ }^{3)}$ Bio-Protection Research Centre, Institute of Fundamental Sciences, College of Sciences, Massey University, Palmerston North 4442, New Zealand

${ }^{4)}$ Department of Genetics, Forestry and Agricultural Biotechnology Institute (FABI), University of Pretoria, Pretoria 0002, South Africa

${ }^{*}$ Equally contributing senior authors

Keywords: Mycosphaerella dearnessii, mating type markers, microsatellite, cross-species amplification, fungi, forest pathogen

Corresponding author: *janousek.jose@gmail.com

Short title: Molecular markers for Lecanosticta acicola 


\begin{abstract}
Lecanosticta acicola is an ascomycete that causes brown spot needle blight of pine species in many regions of the world. This pathogen is responsible for a major disease of Pinus palustris in the USA and is a quarantine organism in Europe. In order to study the genetic diversity and patterns of spread of L. acicola, eleven microsatellite markers and two mating type markers were developed. An enrichment protocol was used to isolate microsatellite-rich DNA regions and 18 primer pairs were designed to flank these regions, of which eleven were polymorphic. A total of 93 alleles were obtained across all loci from forty isolates of $L$. acicola from the USA with an allelic diversity range of 0.095 to 0.931 per locus. Cross-species amplification with some of the markers was obtained with $L$. gloeospora, L. guatemalensis and Dothistroma septosporum, but not with D. pini. Mating type (MAT) markers amplifying both idiomorphs were also developed to determine mating type distribution in populations. These markers were designed based on alignments of both idiomorphs of nine closely related plant pathogens and a protocol for multiplex PCR amplification of the MAT loci was optimised. The MAT markers are not species specific and also amplify the MAT loci in Dothistroma septosporum, D. pini, L. gloeospora and L. guatemalensis. Both types of genetic markers developed in this study will be valuable for future investigations of the population structure, genetic diversity and invasion history of L. acicola on a global scale.
\end{abstract}


Lecanosticta acicola (Thüm.) Syd. (syn: Mycosphaerella dearnessii M. E. Barr) is a haploid ascomycete causing brown spot needle blight of various pine species. L. acicola is thought to be native in Central America where it occurs on pine species growing in tropical and temperate zones (Evans 1984) and in the South-Eastern USA where brown spot needle blight is the major disease on Pinus palustris Mill. (Sinclair and Lyon 2005). L. acicola has also been found on other continents including South America (Gibson 1980), Asia (Suto and Ougi 1998) and Europe (Anonymous 2008).

The global movement and introductory pathways of $L$. acicola are poorly understood (Huan et al. 1995). Microsatellites are useful genetic markers to detect genetic variation within and between populations and can be used to infer migration pathways and histories of the invasions of plant pathogens (e.g. Fontaine et al. 2013).

The aims of this study were to develop polymorphic microsatellite markers for L. acicola that can be used to determine the genetic diversity of populations, as well as mating type markers designed to determine mating type distribution in populations. Cross-species amplifications of the microsatellite and mating type markers were tested on the phylogenetically related pine needle pathogens, Dothistroma septosporum (G. Dorog.) M. Morelet, D. pini Hulbary, Lecanosticta gloeospora H. Evans and L. guatemalensis Quaedvlieg \& Crous.

To screen for microsatellite rich regions in L. acicola, the FIASCO technique (Fast Isolation by Amplified fragment length polymorphism of Sequences COntaining repeats) was used (Zane et al. 2002). Genomic DNA was extracted from six L. acicola cultures from Estonia, Italy, Japan, Slovenia, Switzerland and the USA following the protocol of Smith and Stanosz (1995) and quantified using a spectrophotometer. Equal concentrations 
of DNA from each isolate were pooled together and $250 \mathrm{ng}$ of DNA was used for one-step digestion-ligation reaction with MseI and AFLP adaptors (Zane et al. 2002). This step was followed by PCR with an optimised number of 23 cycles to avoid over-amplification that leads to high clone redundancy. Enrichment of the amplified DNA was carried out using biotinylated probes $(\mathrm{AC})_{8}$ and $(\mathrm{GA})_{8}$. DNA containing microsatellite repeats was captured with streptavidin MagneSphere paramagnetic particles (Promega, Madison, WI, USA) and washed 4x with SSC solutions for high and 2x for low stringency (Arthofer et al. 2007). Enriched DNA was eluted with pre-warmed sterile water and amplified by PCR using adaptor primers. PCR amplicons were purified with peqGOLD kit (PeqLab, Erlangen, Germany) and cloned using pT257RVector and JM109 competent Escherichia coli cells (Fermentas, Vilnius, Lithuania). The FIASCO protocol and subsequent cloning were performed twice to increase the number of captured DNA regions containing polymorphic microsatellites.

In total, over two hundred transformed colonies were inoculated onto master plates and transferred to Nylon membranes (Roche, Mannheim, Germany) following the manufacturers recommendations. This was followed by hybridisation, washing steps and screening to identify transformed $E$. coli colonies containing inserts with simple sequence repeats. Approximately 60 colonies which were expected to contain microsatellite regions were selected and pre-screened with PCR containing $(\mathrm{AC})_{8}$ and $(\mathrm{GA})_{8}$ oligonucleotides as primers (Arthofer et al. 2007). Thirty-nine plasmids showing positive reaction were sequenced and sequence data analysed using BioEdit version 7.1.3 (Hall 1999). Eighteen primer pairs flanking microsatellite rich regions were designed using Primer3 Plus (Untergasser et al. 2007). 
To screen the microsatellite loci for polymorphisms, PCRs were performed with DNA extracted from L. acicola isolates from South Korea, Germany and the USA. PCRs were run in $20 \mu 1$ reaction volumes consisting of. PCR cycling conditions consisted of $2 \mathrm{~min}$ denaturation at $94^{\circ} \mathrm{C}, 35$ cycles including $94^{\circ} \mathrm{C}$ for $30 \mathrm{~s}, 55^{\circ} \mathrm{C}$ for $45 \mathrm{~s}$ and $72^{\circ} \mathrm{C}$ for $60 \mathrm{~s}$, and an extension step at $72^{\circ} \mathrm{C}$ for $15 \mathrm{~min}$. The annealing temperature was decreased to $48^{\circ} \mathrm{C}$ for the primer pair MD12. Amplicons were sequenced to verify the presence of the microsatellite repeat and to determine the polymorphism of the repeat length. One primer of each of the eleven primer pairs amplifying polymorphic regions was fluorescently labelled (Table 1; Applied Biosystems, Cheshire, UK) for fragment analyses.

The efficacy of the 11 labelled polymorphic microsatellite markers was tested on a population of 40 isolates of $L$. acicola obtained from diseased $P$. palustris needles collected in Mississippi, USA. Single PCRs were performed in $8 \mu 1$ volumes (as above) and annealing temperatures were optimised for each primer pair. PCR products were pooled into two panels for fragment analyses according to Table 1. Pooled PCR products were loaded on an ABI 3730XL (Applied Biosystems) and sized with LIZ 500 standard. Alleles were scored using programs GeneMapper 4.1 and PeakScanner (Applied Biosystems). A total of 93 alleles were obtained across all 11 loci ranging from between two to 19 alleles per locus (Table 1). Allelic diversity (Nei 1973), calculated using PopGene 1.31 (http://www.ualberta.ca/ fyeh/popgene.html), ranged between 0.095 and 0.931 per locus with an average heterozygosity of 0.65 over 11 loci. Pairwise linkage disequilibrium $(\mathrm{P}<0.05)$ tested across all loci following 1000 randomisations using Multilocus v1.3b (Agapow and Burt 2001) showed no evidence of linked loci.

Cross-species amplification of the 11 markers was tested on other closely related species, including two isolates of D. septosporum from the Czech Republic, one isolate of D. pini 
Table 1 PCR-based microsatellite markers developed for Lecanosticta acicola.

\begin{tabular}{|c|c|c|c|c|c|c|c|c|c|c|}
\hline $\begin{array}{l}\text { Locus } \\
\text { name }\end{array}$ & Primer name & Primer sequence $\left(5^{\prime}-3^{\prime}\right)$ & Panel & Repeat motif & $\begin{array}{l}\text { Size of } \\
\text { cloned } \\
\text { allele (bp) }\end{array}$ & $\begin{array}{l}\text { GenBank } \\
\text { Accession } \\
\text { no. }\end{array}$ & $\begin{array}{l}\mathrm{T}_{\mathrm{a}} \\
\left({ }^{\circ} \mathrm{C}\right) \dagger\end{array}$ & $\begin{array}{l}\text { Alleles size } \\
\text { range (bp) }\end{array}$ & $\begin{array}{l}\text { No. of } \\
\text { observe } \\
\text { d alleles }\end{array}$ & $\begin{array}{l}H \\
(\mathrm{~N}=40)^{*}\end{array}$ \\
\hline \multirow[t]{2}{*}{ MD1 } & MD1F & GTTTGAGACACTGACTTGACC & A & $(\mathrm{GA})_{9}$ & 148 & KF246553 & 56 & $149-153$ & 3 & 0.5212 \\
\hline & MD1R-(PET) & CACCACCATGGATGGATAGA & & & & & & & & \\
\hline \multirow[t]{2}{*}{ MD2 } & MD2F-(FAM) & СTTACTCCCGAGACTGGATTG & A & $(\mathrm{TC})_{8}$ & 103 & KF246554 & 56 & $97-105$ & 4 & 0.2663 \\
\hline & MD2R & CCAGACCAAGAACGAAGAAA & & & & & & & & \\
\hline \multirow[t]{2}{*}{ MD4 } & MD4F-(NED) & ATCCGGATCTTGACCTCCT & B & $(\mathrm{CT})_{14}$ & 169 & KF246555 & 58 & $155-169$ & 3 & 0.3038 \\
\hline & MD4R & CGGTAACTTCTCGCAACCT & & & & & & & & \\
\hline \multirow[t]{3}{*}{ MD5 } & MD5F-(VIC) & & B & $(\mathrm{CT})_{2}(\mathrm{TC})_{8} \mathrm{~T}(\mathrm{TC})_{3} \mathrm{~T}(\mathrm{TC})_{4} \mathrm{TT}$ & 290 & KF246556 & 57 & $286-288$ & 2 & 0.095 \\
\hline & & CAGGCACAAGGAGAAAGAGA & & $(\mathrm{TC})_{2}$ & & & & & & \\
\hline & MD5R & TCCTCAAGACTCCTCACCTG & & & & & & & & \\
\hline \multirow[t]{2}{*}{ MD6 } & MD6F-(VIC) & AGAGTAAGGGAAAGGAAGAGA & A & $(\mathrm{GA})_{7} \mathrm{AA}(\mathrm{GA})_{9}(\mathrm{GAA})_{13}$ & 169 & KF246557 & 61 & $129-205$ & 19 & 0.9270 \\
\hline & MD6R & CGGCTACCGTCCTAATCTAAC & & & & & & & & \\
\hline \multirow[t]{2}{*}{ MD7 } & MD7F-(PET) & CCAACCCGTCAATCAGAA & A & $(\mathrm{CT})_{12}$ & 298 & KF246558 & 56 & $296-328$ & 11 & 0.8350 \\
\hline & MD7R & CGAGAGCGCGAGAAAGTA & & & & & & & & \\
\hline \multirow[t]{2}{*}{ MD8 } & MD8F-(FAM) & CACAGCACGGAAGACACGAG & B & $(\mathrm{GA})_{20}$ & 337 & KF246559 & 60 & $303-366$ & 17 & 0.9307 \\
\hline & MD8R & TCTGTTTCTGAGCGGTAGGAG & & & & & & & & \\
\hline \multirow[t]{2}{*}{ MD9 } & MD9F-(NED) & GGGAACACACGCTCTTTG & A & $(\mathrm{GT})_{9}$ & 220 & KF246560 & 56 & $218-236$ & 8 & 0.8213 \\
\hline & MD9R & $\begin{array}{l}\text { GGGCAAGAAATCCAGGAC } \\
\text { CCTACCTACTTCCCTTTATATC }\end{array}$ & & & & & & & & \\
\hline \multirow[t]{2}{*}{ MD10 } & MD10F-(PET) & $\mathrm{TCC}$ & B & $(\mathrm{CT})_{3}(\mathrm{TATAAC})_{13}$ & 224 & KF246561 & 58 & $209-232$ & 12 & 0.8638 \\
\hline & MD10R & TTAGGACGGTAGCCGTAGAG & & & & & & & & \\
\hline \multirow[t]{2}{*}{ MD11 } & $\begin{array}{l}\text { MD11F- } \\
\text { (FAM) }\end{array}$ & GTGGGATGTTTGTTGGGTAG & B & $(\mathrm{TGG})_{3}(\mathrm{GGGAAAT})_{10}(\mathrm{GTT})_{3}$ & 195 & KF246562 & 58 & $161-197$ & 7 & 0.7622 \\
\hline & MD11R & GCCACCACAGATTGGATAAC & & & & & & & & \\
\hline \multirow[t]{2}{*}{ MD12 } & MD12F-(VIC) & AGTCATAAAGAACCAGGA & B & $(\mathrm{GA})_{14}$ & 124 & KF246563 & 48 & $119-133$ & 7 & 0.7812 \\
\hline & MD12R & GCTATCTAGGCCATTGAA & & & & & & & & \\
\hline
\end{tabular}

${ }^{*} H$ - gene diversity (Nei, 1973) calculated on the population represented by 40 isolates.

$\dagger$ - Annealing temperature. 
from Ukraine and one from USA, four isolates of L. gloeospora from Mexico and nine isolates of L. guatemalensis from Guatemala. Amplification was successful with markers MD2, MD6, MD7, MD9 and MD10 for D. septosporum, whereas none of the markers amplified in D. pini. All markers except MD1, MD4 and MD8 amplified L. gloeospora. L. guatemalensis was amplified with all markers except for MD5, MD8, MD10 and MD12. In order to develop markers that amplify the MAT regions of L. acicola, the mating type DNA sequences for each idiomorph of nine species phylogenetically closely related to $L$. acicola (Cercospora beticola, C. zeae-maydis, C. zeina, D. septosporum, D. pini, Mycosphaerella eumusae, M. fijiensis, M. musicola and Passalora fulva), obtained from Genbank (http://www.ncbi.nlm.nih.gov/), were aligned and several different sets of degenerate primers were designed in the conserved regions of each idiomorph of the MAT gene. Two of the degenerate primer sets that worked well (Table 2, Online Resource 1)

Table 2 Mating type primers developed for Lecanosticta acicola.

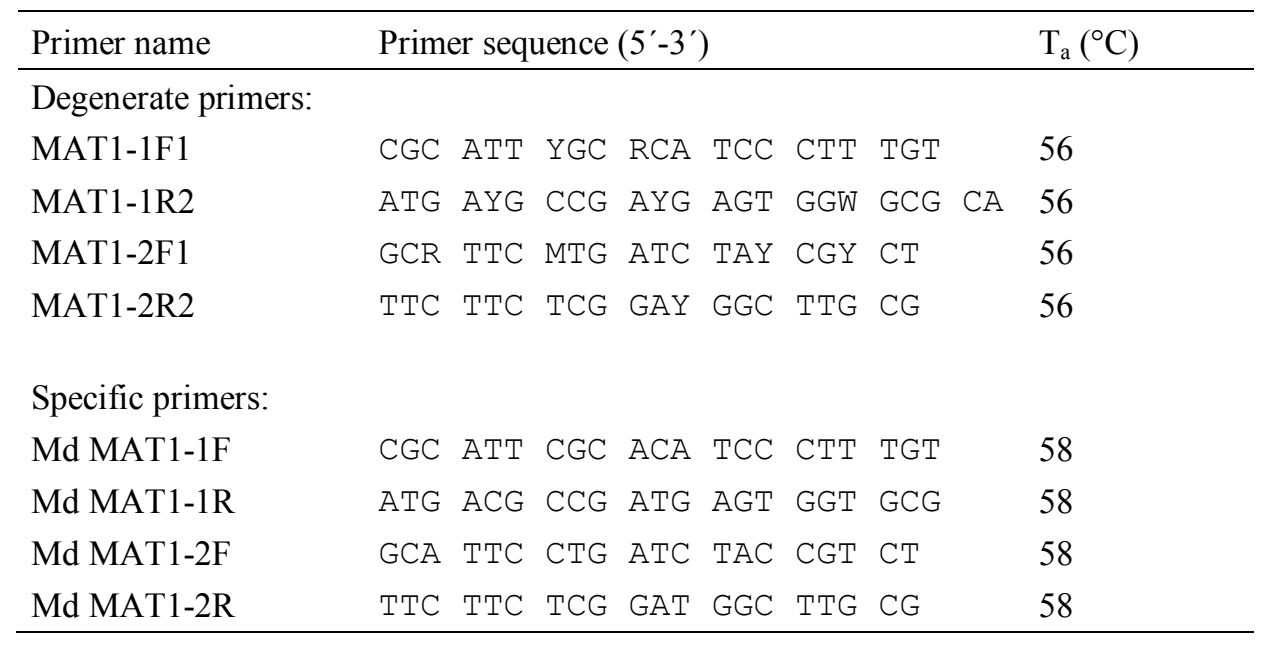

were further optimised and PCR conditions consisted of $7.25 \mu 1 \mathrm{H}_{2} \mathrm{O}, 2.5 \mu 1 \mathrm{MyTaq}^{\mathrm{TM}}$ Mix (Bioline; MA, USA), $0.25 \mu 1$ of each primer, $0.25 \mu 1 \mathrm{MyTaq}^{\mathrm{TM}}$ DNA Polymerase (Bioline) and $2 \mu 1$ of gDNA in a total volume of $12.5 \mu$. Cycling conditions consisted of $10 \mathrm{~min}$ 
denaturation at $94^{\circ} \mathrm{C}, 40$ cycles of $30 \mathrm{~s}$ at $94^{\circ} \mathrm{C}, 45 \mathrm{~s}$ at $56^{\circ} \mathrm{C}, 45 \mathrm{~s}$ at $72^{\circ} \mathrm{C}$ and a last extension at $72^{\circ} \mathrm{C}$ for $10 \mathrm{~min}$. PCR products were sequenced using forward and reverse primers to confirm correct amplification of the partial MAT gene and sequence data were analysed using CLC Main Workbench 6.0. The primers were redesigned without degenerate nucleotides ('specific' primers) according to the sequence results obtained (Table 2, Online Resource 1). PCR conditions were the same as for the degenerate primers except for the annealing temperature that was increased to $58^{\circ} \mathrm{C}$.

Multiplexing of specific primer sets for both MAT idiomorphs was optimised to decrease the number of reactions and time required for large scale population screenings. Genomic DNA from two isolates of different mating types was pooled and amplified in a single PCR tube to verify there is no competition between the primers. Multiplexing was optimised using Fast Start chemistry: $12.5 \mu 1$ reaction mix composed of $7.9 \mu 1 \mathrm{H}_{2} \mathrm{O}, 1.25 \mu 1$ FastStart PCR Buffer (Roche, Mannheim, Germany), $0.25 \mu 1$ 10mM nucleotide mix, $0.5 \mu 1$ of each primer, $0.1 \mu$ FastStart Taq DNA Polymerase (Roche) and $2 \mu 1$ of gDNA using the same cycling conditions as described above. Amplification of both partial idiomorphs was visualised on 2\% agarose gel under UV light (Online Resource 2). The population of $L$. acicola from Mississippi was screened using multiplex PCR. The MAT primers were also tested for the amplification success on the identical isolates of two species of Dothistroma, L. gloeospora and L. guatemalensis as for microsatellite markers.

The newly designed 'specific' mating type primers amplified regions of both idiomorphs of the MAT gene and were confirmed with sequencing. The MAT1-1-1 amplicon of $560 \mathrm{bp}$ in length (GenBank accession no. KF688139) showed 79\% nucleotide identity and 55\% amino acid identity with Dothistroma pini MAT1-1-1. The 288 bp MAT1-2 amplicon (GenBank accession no. KF688140) showed only 66\% nucleotide similarity with that of $D$. 
pini. The correct amplification of the MAT1-2 was, therefore, confirmed by the presence of an intron in the conserved amino acid serine, common to all ascomycetes (Online Resource 1; Arie et al. 1997).

Correct amplification of each idiomorph of the MAT gene revealed that L. acicola is heterothallic. Amplification of both partial idiomorphs in a single PCR mix to which DNA of both mating types were added confirmed that there is no competition between the primer pairs. The MAT markers developed for L. acicola in this study successfully amplified the respective mating type idiomorphs in all 40 isolates tested. Results revealed the presence of 22 MAT1-1 and 18 MAT1-2 isolates in the collection of isolates from Mississippi, strongly indicating a sexual mode of reproduction in this population. Furthermore, both primer sets successfully amplified MAT sequences from related fungi, including both species of Dothistroma tested. All four isolates of L. gloeospora were identified as having the MAT11-1 locus and L. guatemalensis revealed the presence of both mating types ( 7 isolates possessed the MAT1-1-1 locus and 2 isolates the MAT1-2 locus). Thus the MAT markers are not species specific and are likely to be useful for identification of mating types in other closely related taxa, such as the recently described species of Lecanosticta from Central America (Quaedvlieg et al. 2012).

We have shown that the eleven microsatellite markers developed in this study are robust and will be useful for future population studies of L. acicola. In addition, we have also provided a tool whereby the mating type and mating type distribution of the isolates in a population can be determined. This will be applicable for investigations of global population diversity and structure of L. acicola. 


\section{Acknowledgements}

The authors thank Carole Flyger and Dagmar Palovčíková for technical assistance; Dana Nelson for needle samples, and Coralie Bertheau, Hannes Schuler, Erhard Halmschlager and Tuan Duong for useful comments on the work. We acknowledge financial support to Josef Janoušek from the AKTION Czech Republic - Austria (project 58p23), the Scholarship Foundation of the Republic of Austria (OeAD-GmbH, Austria), the Hlavka Foundation (Czech Republic; for internship at Massey University, New Zealand) and the Intern Grant Agency of Faculty of Forestry and Wood Technology (Mendel University in Brno, Czech Republic). The project was supported financially by COST CZ LD12031 (DIAROD), the FPS COST Action FP1102 (DIAROD) and the European Union's Seventh Framework Programme FP7 2007-2013 (KBBE 2009-3) under grant agreement 245268 ISEFOR.

\section{References}

Agapow, P.-M. and Burt, A., 2001. Indices of multilocus linkage disequilibrium. Molecular Ecology Notes, 1, pp.101-102.

Anonymous, 2008. Mycosphaerella dearnessii and Mycosphaerella pini. EPPO Bulletin, 46, pp.349-362.

Arie, T. et al., 1997. Efficient cloning of ascomycete mating type genes by PCR amplification of the conserved MAT HMG Box. Fungal Genetics and Biology, 21, pp.118130. 
Arthofer, W. et al., 2007. Lessons from a beetle and an ant: coping with taxon-dependent differences in microsatellite development success. Journal of Molecular Evolution, 65, pp.304-307.

Evans, H.C., 1984. The genus Mycosphaerella and its anamorphs. Mycological Papers, 153, pp.1-103.

Fontaine, M.C. et al., 2013. History of the invasion of the anther smut pathogen on Silene latifolia in North America. The New Phytologist, 198, pp.946-956.

Gibson, I.A.S., 1980. Two pine needle fungi new to Colombia. Tropical Pest Management, 26, pp.38-40.

Hall, T.A., 1999. BioEdit: a user-friendly biological sequence alignment editor and analysis program for Windows 95/98/NT. Nucleic Acids Symposium Series, 41, pp.95-98.

Huan, Z.-Y., Smalley, E.B. and Guries, R.P., 1995. Differentiation of Mycosphaerella dearnessii by cultural characters and RAPD analysis. Phytopathology, 85, pp.522-527.

Nei, M., 1973. Analysis of gene diversity in subdivided populations. Proceedings of the National Academy of Sciences of the United States of America, 70, pp.3321-3323.

Quaedvlieg, W. et al., 2012. DNA barcoding of Mycosphaerella species of quarantine importance to Europe. Persoonia, 29, pp.101-115.

Sinclair, W. and Lyon, H. H., 2005. Diseases of trees and shrubs 2nd ed., Cornell University Press. 
Smith, D.R. and Stanosz, G.R., 1995. Confirmation of two distinct populations of Sphaeropsis sapinea in the North Central United States using RAPDs. Phytopathology, 85, pp. 699-704.

Suto, Y. and Ougi, D., 1998. Lecanosticta acicola, causal fungus of brown spot needle blight in Pinus thunbergii, new to Japan. Mycoscience, 39, pp.319-325.

Untergasser, A. et al., 2007. Primer3Plus, an enhanced web interface to Primer3. Nucleic acids research, 35(Web Server issue), pp.W71-4.

Zane, L., Bargelloni, L. and Patarnello, T., 2002. Strategies for microsatellite isolation: a review. Molecular Ecology, 11, pp.1-16. 


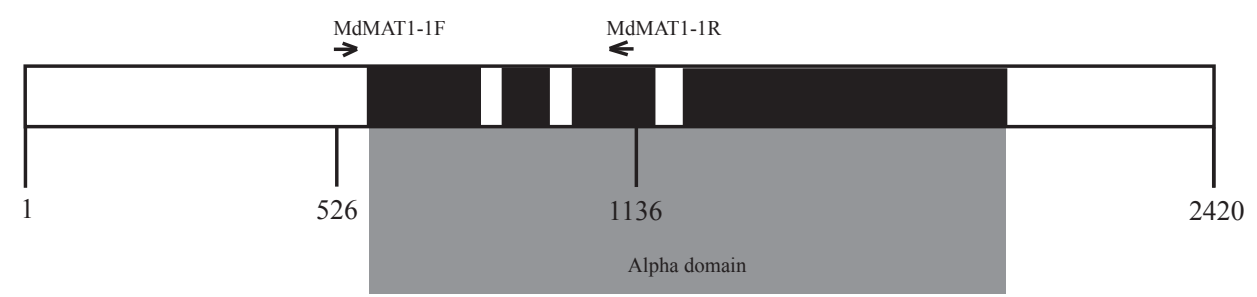

D. pini MAT1-2

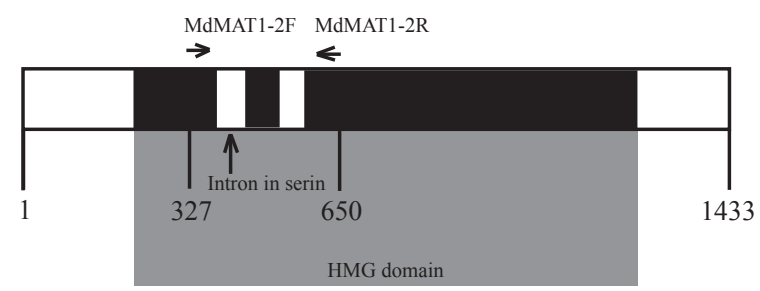

$\overline{100 \mathrm{bp}}$

Online Resource 1 Positions of the specific mating type primers. Primer positions are indicated (arrows) in full-length idiomorphs of the putative MAT gene of D. pini (GenBank No.: DQ915449.1, DQ915451.1) as the complete L. acicola MAT region sequences are not available. Putative genes (alpha domain-containing and HMG domain-containing) are represented by grey boxes; coding sequences are represented by black boxes. 


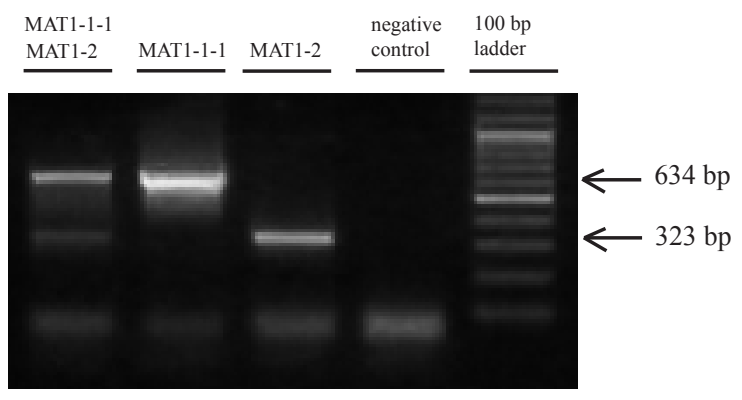

Online Resource 2 PCR amplicons of parts of the MAT1-1-1 and MAT1-2 idiomorphs of Lecanosticta acicola obtained using the MAT primers in multiplex PCR. 